\title{
Comorbid Psychopathology and Alcohol Use Patterns among Methadone Maintenance Treatment Patients
}

\author{
Georgios Moussas, ${ }^{1}$ Irene Fanouraki, ${ }^{1}$ Argiro Pachi, ${ }^{1}$ Arezina Asomatou, ${ }^{1}$ \\ Olga Drylli, ${ }^{1}$ Georgios Paschalakis, ${ }^{1}$ Athanasios Tselebis, ${ }^{1}$ Konstantinos Giotakis, ${ }^{1}$ \\ Dionisios Bratis, ${ }^{1}$ Georgios Dermatis, ${ }^{2}$ and Meni Malliori ${ }^{3}$ \\ ${ }^{1}$ Psychiatric Department, "Sotiria” General Hospital of Chest Disease, Mesogeion 152, 11527 Athens, Greece \\ ${ }^{2}$ Organization against Drugs (OKANA), Mesogeion 152, 11527 Athens, Greece \\ ${ }^{3}$ Department of Psychiatry, Athens University Medical School, Vas. Sofias 72-74, 11528 Athens, Greece
}

Correspondence should be addressed to Athanasios Tselebis; atselebis@yahoo.gr

Received 30 December 2014; Revised 27 February 2015; Accepted 8 March 2015

Academic Editor: Gallus Bischof

\begin{abstract}
Copyright (C) 2015 Georgios Moussas et al. This is an open access article distributed under the Creative Commons Attribution License, which permits unrestricted use, distribution, and reproduction in any medium, provided the original work is properly cited.

130 patients from a methadone maintenance treatment program agreed to complete Symptoms Checklist 90-Revised (SCL90R) and Alcohol Use Disorders Identification Test (AUDIT) self-report scales. Scores higher than the proposed cut-score on SCL-90R scale were observed on depression, obsessions-compulsions, paranoid ideation, anxiety, anger-hostility, somatization, interpersonal sensitivity, and psychoticism subscales. In sum, $42.9 \%$ of our sample exhibited depressive symptomatology, $34.9 \%$ obsessive-compulsive symptoms, $29.1 \%$ somatization, $27.2 \%$ anxiety symptoms, $22.2 \%$ paranoid ideation, $19 \%$ phobic anxiety, $15.1 \%$ psychoticism, and $15.1 \%$ hostility and $11.9 \%$ presented with symptoms of interpersonal sensitivity. Mean score on AUDIT scale was $6.9 \pm 7.9 .63 .0 \%$ of our participants scored below cut-off and were classified as having a low level of alcohol-related problems; $24.4 \%$ scored in the range of $8-15$ which is an indication of alcohol abuse whereas $12.6 \%$ scored 16 and above indicative of serious abuse/addiction. Scores on AUDIT scale were positively correlated with length of time on methadone treatment, but not with length of time on drug use or age of our participants. Positive correlations were observed among AUDIT and SCL-90R scores, namely, with global severity index score, positive symptom distress index, positive symptom total, and all primary symptom dimensions subscales except phobic anxiety.
\end{abstract}

\section{Introduction}

Substance abuse and dependence, especially opioid dependence, contribute significantly to the global burden of disease in Greece [1]. According to the Greek Documentation and Monitoring Centre for Drugs (EKTEPN) a rising trend in the use of all illegal drugs was observed during the last 30 years in Greece among 15-19-year-old students [2]. In 2011 the Nationwide School Population Survey on Alcohol and Other Drugs in Greece stated that 1.3\% in this juvenile age group reported past heroin use [3]. The estimated number of drug users, aged 15-64 years and reporting heroin as primary drug, was 22,515 for the year 2010 in Greece [4].

Applying harm reduction policies and attempting to aid drug users who failed to benefit from abstinence "drug-free" treatment programs led to the development of the Organisation against Drugs (OKANA) in 1995, with 54 Substitution Treatment Units and a total of 9.878 persons in substitution treatment in Greece in 2012. 27.1\% of individuals were in methadone and $72.9 \%$ in buprenorphine Substitution Treatment Units in 2012 [5]. During the same year 2,136 addicts requested entry to the substitution programs, while 4,275 persons were already on the waiting list since 2011 [6]. Most of them reported polysubstance abuse (74\%), with heroin as a primary drug of abuse (77.5\%) [5].

The high prevalence of concomitant psychiatric disorders [7-10] and alcohol abuse [11] among drug users far exceeds general population estimates and complicates the picture raising issues not extensively studied by prior international and Greek literature. While figures vary greatly, it has been 
estimated that between 28 and $76 \%$ of methadone maintained patients have at least one comorbid psychiatric disorder [12-14], while alcohol abuse ranges between 8 and 50\% during maintenance treatment, being $10-90 \%$ before entering treatment [10].

Addiction and psychological disorders have bilateral correlation. Studies report that there are significant associations between the current measure of psychological distress on methadone maintained patients and both illegal substance use and alcohol use [15-20]. Higher comorbidity and severity of psychopathology were also correlated with family-social problems and employment status [21].

Several other studies indicate that drug-dependent subjects with current problematic substance use and coexisting psychopathology undergoing methadone maintenance require higher methadone dosages on treatment programs [22-24] tend to remain in treatment longer [25] and generally have reduced health-related quality of life [26].

Coexisting psychopathology has a further negative influence on health-related quality of life [27] and it is reasonable to assume that recognizing and treating it may also improve health-related quality of life in this population [28]. Such being the case, remaining on methadone maintenance treatment programs most likely effectuates long-term improvements in quality of life in these patients $[29,30]$.

Studies include psychiatric disorders as causes of addicts' rehabilitation failure [31-34]. According to literature, the more the psychopathology of drug addicts, the greater the need for therapeutic interventions [35]. Severity of psychopathology complicates treatment and subjects with less severe comorbidity respond optimally in psychotherapeutic interventions [36]. Other isolated studies [37-40] could not confirm the assumption that opiate users with psychiatric comorbidity are more vulnerable in the long-term course of addiction. Either way recent reports $[41,42]$ state that comorbid patients seem to have special treatment needs requiring additional psychopharmacological and psychotherapy treatments.

The present study aims at investigating the presence of psychopathological symptoms and alcohol use patterns among drug addicts receiving methadone maintenance treatment since relevant research in the Greek population has not extensively studied such issues.

\section{Materials and Methods}

2.1. Sample-Procedure. 130 randomly selected individuals from a population list of 300 methadone maintenance patients treated in the 4th Substitution Unit of OKANA in Athens agreed to complete Symptoms Checklist 90Revised (SCL-90R) and Alcohol Use Disorders Identification Test (AUDIT) self-report scales, during one year. Research Randomizer [43] was used to draw a random sample of participants from the population list.

Participants were informed that all study information would be kept confidential, participation (or lack thereof) would not affect their treatment, and participation was voluntary, based on verbal informed consent. All interviews were conducted by personnel separate from clinic staff in a private room at the outpatient clinic. Ethics approval was not necessary given that the nonexperimental design did not expose subjects to risks. Additionally, subjects were informed of the study's goals and procedures. Data were recorded and handled anonymously.

\subsection{Psychological Measures}

2.2.1. SCL-90R. The SCL-90R is a 90 -item self-report symptom inventory designed to reflect psychological symptom patterns of psychiatric and medical patients. Each item of the questionnaire is rated on a 5-point scale of distress from 0 (none) to 4 (extreme). The SCL-90R consists of the following nine primary symptom dimensions: somatization (SOM, which reflects distress arising from bodily perceptions), obsessions-compulsions (OC, which reflects obsessions-compulsions symptoms), interpersonal sensitivity (IS, which reflects feelings of personal inadequacy and inferiority in comparison with others), depression (DEP, which reflects depressive symptoms, as well as lack of motivation), anxiety (ANX, which reflects anxiety symptoms and tension), hostility (HOS, which reflects thoughts, feelings, or actions that are characteristic of negative affective states of anger, aggression, irritability, rage, and resentment), phobic anxiety (PHO, which reflects symptoms of persistent fears as responses to specific conditions), paranoid ideation (PAR, which reflects symptoms of projective thinking, hostility, suspiciousness, and fear of loss of autonomy), and psychoticism (PSY, which reflects a broad range of symptoms from mild interpersonal alienation to dramatic evidence of psychosis) [44-46].

The SCL-90 takes between 12 and 20 min to complete. With regard to its reliability, the internal consistency coefficient $\alpha$ values for the nine symptom dimensions ranged from a low of 0.77 for psychoticism to a high of 0.90 for depression. Additionally, the few validity studies of the SCL90R demonstrate that this scale has equal validity compared with other self-report inventories. The SCL-90R has been standardized and used in the Greek population and its reliability (Cronbach's $\alpha$ ) for the total of the items is 0.97 [47-50]. The cut-off for the SCL-90R subscales is 0.99 [51]. T scores have a normal mean of 50 and a standard deviation of 10. The cut-off level indicating clinically significant problems was set to $T \geq 70[52,53]$. These are reported in the descriptive statistics for the sample.

The inventory was completed in the presence of psychologists who provided clarifications when necessary.

2.3. AUDIT. The Alcohol Use Disorders Identification Test (AUDIT) consists of 10 questions: three questions on use, four on dependence, and three questions about problems related to harmful alcohol use. Each response has a score ranging from 0 to 4 . A total score of $>8$ is an indication of alcohol abuse and a score of $>15$ indicates serious abuse/addiction whilst a score between 8 and 10 is an indication of being at risk, according to the authors [54-57].

2.4. Statistical Analysis. All variables are assessed with the use of descriptive statistics and values are expressed as 
TABLE 1: Mean scores on SCL-90R subscales and on AUDIT scale.

\begin{tabular}{|c|c|c|c|c|c|c|c|}
\hline & Total & $N$ & $\begin{array}{c}\text { Male } \\
N=98\end{array}$ & $N$ & $\begin{array}{l}\text { Female } \\
N=32\end{array}$ & $N$ & $t$-test $P$ \\
\hline Age & $43.34 \pm 8.12$ & 130 & $44.3 \pm 8.30$ & 98 & $40.4 \pm 8.24$ & 32 & 0.010 \\
\hline Years of addiction & $26.07 \pm 7.93$ & 130 & $27.0 \pm 7.67$ & 98 & $23.5 \pm 8.17$ & 32 & 0.021 \\
\hline Depression & $2.00 \pm 0.86$ & 126 & $1.90 \pm 0.84$ & 95 & $2.33 \pm 0.84$ & 31 & 0.016 \\
\hline Obsessions-compulsions & $1.89 \pm 0.88$ & 126 & $1.80 \pm 0.88$ & 95 & $2.15 \pm 0.85$ & 31 & 0.052 \\
\hline Paranoid ideation & $1.73 \pm 0.89$ & 126 & $1.66 \pm 0.90$ & 95 & $1.95 \pm 0.84$ & 31 & 0.109 \\
\hline Anxiety & $1.56 \pm 0.95$ & 125 & $1.43 \pm 0.88$ & 94 & $2.00 \pm 1.06$ & 31 & 0.003 \\
\hline Somatization & $1.40 \pm 0.88$ & 127 & $1.30 \pm 0.81$ & 95 & $1.70 \pm 1.02$ & 32 & 0.024 \\
\hline Hostility & $1.39 \pm 1.05$ & 126 & $1.26 \pm 0.99$ & 95 & $1.81 \pm 1.13$ & 31 & 0.011 \\
\hline Interpersonal sensitivity & $1.29 \pm 0.80$ & 126 & $1.27 \pm 0.78$ & 95 & $1.38 \pm 0.86$ & 31 & 0.505 \\
\hline Psychoticism & $1.21 \pm 0.76$ & 126 & $1.16 \pm 0.73$ & 95 & $1.37 \pm 0.87$ & 31 & 0.191 \\
\hline Phobic anxiety & $0.77 \pm 0.77$ & 126 & $0.68 \pm 0.71$ & 95 & $1.06 \pm 0.89$ & 31 & 0.015 \\
\hline AUDIT & $6.91 \pm 7.96$ & 127 & $6.59 \pm 7.80$ & 96 & $7.90 \pm 9.03$ & 31 & 0.428 \\
\hline
\end{tabular}

the mean \pm standard deviation for continuous variables. Kolmogorov-Smirnov test served as a goodness of fit test indicating the normality of the distribution of our data. A one-sample $t$-test was run to determine whether AUDIT score in recruited subjects was significantly different to Greek general population, defined as AUDIT score of 3.79 [56]. Independent samples $t$-test was used to test for significance of difference between groups based on gender and employment status. One-way ANOVA was used to test for significance of difference among groups based on marital status. Pearson's correlation was used to measure the bivariate associations among continuous variables. To determine the best predictors of the dependent variable "AUDIT" we performed a stepwise multiple regression analysis with length of time on methadone treatment and (from the SCL-90R) whether or not there was psychopathology present as independent variables. Statistical significance was set at $P<0.05$ (twotailed). All analyses were carried out using the statistical package SPSS version 19.

\section{Results}

Of the 130 participants 98 (75.4\%) were males and $32(24.6 \%)$ females. 77 participants $(59.23 \%)$ reported being single, 25 (19.23\%) divorced, 23 (17.7\%) married, and 5 (3.8\%) widowed. 80 participants $(61.5 \%)$ reported having no children whereas $50(38.5 \%)$ of them reported having at least one. The vast majority of our sample stated being unemployed, $106(81.53 \%)$, whereas only $24(18.46 \%)$ reported having a job. Mean age of our sample was $43.34 \pm 8.11$, mean years of education were $10.34 \pm 3.02$, and mean length of time on drug use was $26.07 \pm 7.93$ years and on methadone treatment $6.69 \pm 4.18$ years.

In almost all subscales of the SCL-90R mean scores were $>1$ (Table 1). Highest mean score was observed in depressive dimension of the SCL-90R and lowest one in phobic anxiety (Table 1).

Mean AUDIT score of our sampled population (6.91 \pm 7.96) was higher than the Greek general population AUDIT score of 3.79 [56], a statistically significant difference of 3.12
$(95 \% \mathrm{CI}, 1.73$ to $4.52, t(126)=4.421$, and $P<0.0005)$ (Table 1).

Only $6.4 \%$ of our sample scored within normal range on all nine factors of the SCL-90R scale. On the contrary, $42.9 \%$ of our participants reported symptoms over the cut-score on depressive symptomatology, whereas $34.9 \%$ presented with obsessions-compulsions symptoms (Figure 1).

$24.4 \%$ of our sample scored in the range of $8-15$ on AUDIT scale as an indication of alcohol abuse, and $12.6 \%$ scored $>15$ indicating serious abuse/addiction. 3.9\% scored in the range of 16-19 indicating a high level of alcohol problems, and $8.7 \%$ scored $>20$ indicating possible dependence (Table 2).

As to gender the female population of our sample scored significantly higher on anxiety, hostility, depression, phobic anxiety, and somatization. Females were also significantly younger than males $(40.4$ versus $44.3 P<0.05)$ and had less mean length of time on drug use $(23.5$ versus $27.0 P<0.05)$ (Table 1).

Drug addicts of our sample on parenthood $(N=50)$ scored higher on depression $(2.2$ versus $1.8 P<0.05)$ and somatization $(1.6$ versus $1.3 P<0.05)$ compared to others without parental responsibilities.

Lower levels for anxiety (1.19 versus $1.65, P<0.05)$ and paranoid ideation (1.37 versus 1.81, $P<0.05)$ were noted among employed individuals of our sample $(N=$ 24). Divorced or separated subjects exhibited higher rates on AUDIT scale versus married ones (11.17 versus 4.52, ANOVA Bonferroni $P<0.05$ ).

Age was negatively correlated with anxiety, paranoid ideation, phobic anxiety, hostility, and interpersonal sensitivity subscales (Table 3 ).

Education level and length of time on drug use were not correlated with psychopathology scales. A trend towards negative correlation was noted for paranoid ideation and length of time on methadone treatment.

Positive correlations were observed among scores on AUDIT scale and scores on all subscales of SCL-90R, except for phobic anxiety (Table 3). Also scores on AUDIT were 
TABLE 2: Percentages of pathological values in SCL-90R and AUDIT.

\begin{tabular}{|c|c|c|c|c|c|c|}
\hline \multicolumn{7}{|c|}{ SCL-90R } \\
\hline & \multirow{2}{*}{$N$} & \multicolumn{4}{|c|}{ Raw scores } & \multirow{2}{*}{$\begin{array}{l}T \text { score } \\
T \geq 70\end{array}$} \\
\hline & & $0-1$ & $1^{+}-2$ & $2^{+}-3$ & $3^{+}-4$ & \\
\hline Somatization & 127 & $39.4 \%$ & $39.3 \%$ & $15.8 \%$ & $5.5 \%$ & $29.2 \%$ \\
\hline Obsessions-compulsions & 126 & $18.3 \%$ & $38.8 \%$ & $33.4 \%$ & $9.5 \%$ & $34.9 \%$ \\
\hline Interpersonal sensitivity & 126 & $39.7 \%$ & $43.6 \%$ & $14.6 \%$ & $2.3 \%$ & $11.9 \%$ \\
\hline Depression & 126 & $15.9 \%$ & $33.3 \%$ & $38.9 \%$ & $11.9 \%$ & $42.9 \%$ \\
\hline Anxiety & 125 & $34.4 \%$ & $38.4 \%$ & $18.4 \%$ & $8.4 \%$ & $27.2 \%$ \\
\hline Hostility & 126 & $42.9 \%$ & $32.5 \%$ & $16.7 \%$ & $7.9 \%$ & $15.1 \%$ \\
\hline Phobic anxiety & 126 & $71.4 \%$ & $19.1 \%$ & $9.2 \%$ & $0.0 \%$ & $19 \%$ \\
\hline Paranoid ideation & 126 & $25.4 \%$ & $42.1 \%$ & $24.6 \%$ & $7.9 \%$ & $22.2 \%$ \\
\hline Psychoticism & 126 & $42.1 \%$ & $45.0 \%$ & $9.7 \%$ & $5.2 \%$ & $15.1 \%$ \\
\hline \multicolumn{7}{|c|}{$\operatorname{AUDIT}(N=127)$} \\
\hline \multicolumn{2}{|c|}{$0-7$} & \multicolumn{5}{|c|}{$63 \%$} \\
\hline \multicolumn{2}{|c|}{ Indication of alcohol abuse (AUDIT 8-15) } & \multicolumn{5}{|c|}{$24.4 \%$} \\
\hline \multicolumn{2}{|c|}{ Serious abuse/addiction (AUDIT > 15) } & \multicolumn{5}{|c|}{$12.6 \%$} \\
\hline
\end{tabular}

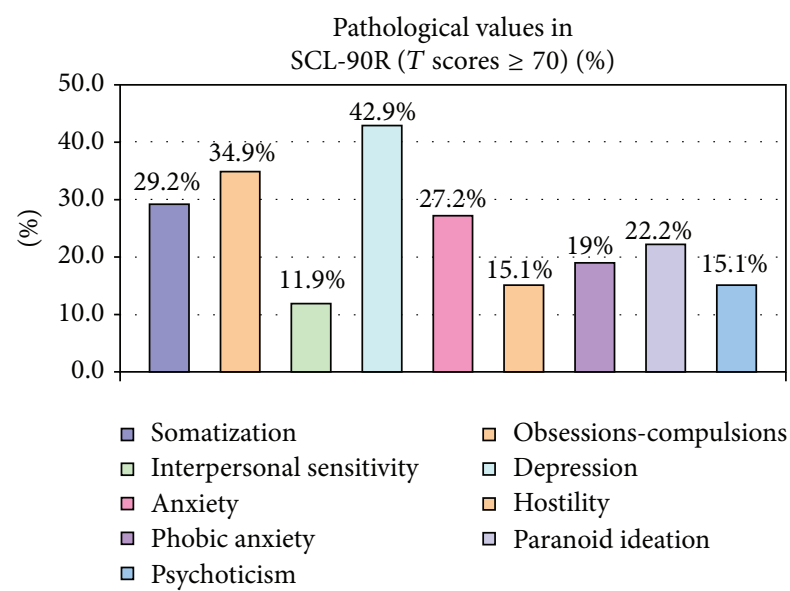

FIGURE 1

positively correlated with length of time on methadone treatment.

Stepwise multiple regression analysis was conducted to identify the best predictors of the dependent variable "scores on AUDIT scale" among the independent variables "scores on subscales of SCL-90R" and "length of time on methadone treatment" and to examine their contribution to the variation (expressed as $R^{2}$ ) in the dependent variable. The final regression model showed that from all variables entered into the equation "somatization subscale from SCL-90R" and "years on methadone treatment" were significant predictors of "scores on AUDIT scale" $\left(F_{2,117}=8.625, P<0.001\right)$. "Somatization subscale from SCL-90R" explained 9\% of the variance and "years on methadone treatment" accounted for an additional $4 \%$ of the variance of AUDIT scores ( $\beta$ coefficient 0.36 $P=0.023)$.

\section{Discussion}

The results from the present study are largely consistent with findings from other studies $[58,59]$ that assessed current levels of general psychopathology with SCL-90R as a diagnostic screening tool, suggesting that patients on methadone maintenance treatment have high rates of psychopathological symptoms and female patients are in particular distress [6062]. According to a recent article [63], among the demographic variables, age significantly differentiated patients, as sensitive-psychotic, violent/suicidal, and panic addicts proved to be younger, whereas older heroin addicts were distinguished by higher scores for somatization and worthlessness. Our results reporting age being negatively correlated with anxiety, paranoid ideation, phobic anxiety, hostility, and interpersonal sensitivity subscales are in agreement with the study mentioned above.

Yet, unlike other reports $[59,64]$, our sample was characterized by remarkably high levels of unemployment (81.53\%), possibly reflecting the lack of social supportive systems in our country and social stigma along with high rates of psychopathology evidenced in these people (only $6.4 \%$ of our sample scored within normal range on SCL-90R subscales) rendering them unable to claim a position in the marketplace.

The fact that the largest proportion of our sample reported being unmarried or divorced and without any children highlights some of the social consequences of addiction, affecting their family environment [65]. Earlier reports state that addicted individuals with higher social adjustment (i.e. married, better educated, and employed) had lower risk of relapse to daily illicit drug use $[66,67]$. In our sample in agreement with other findings $[39,68]$ single patients had higher average scores on all domains of psychopathology compared to married ones, however, with no significant discrepancy. Divorced or separated subjects exhibited higher scores on AUDIT scale possibly reflecting 


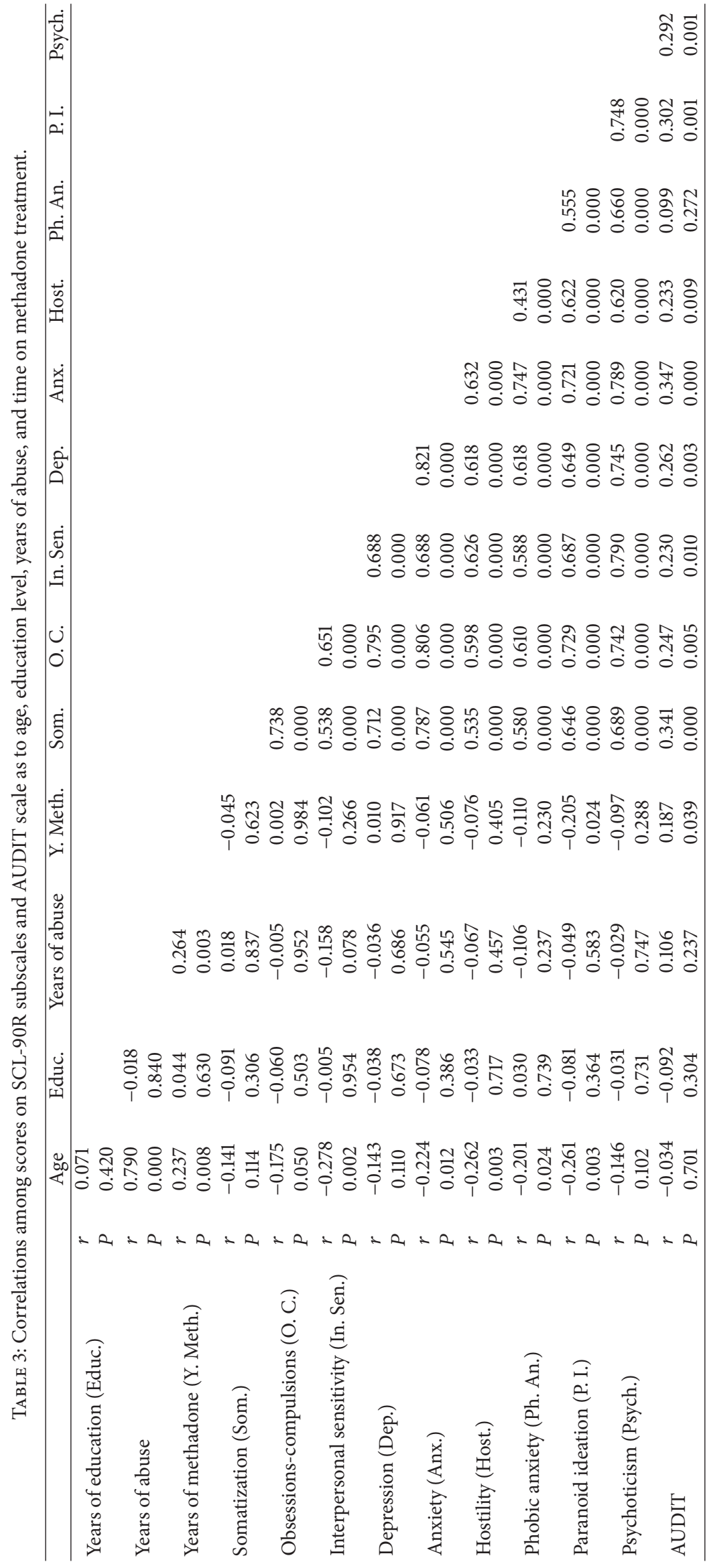


the role of interpersonal determinants in alcohol abuse [15, 69].

Further studies $[58,59]$ ranked depressive symptomatology first among methadone patients in treatment and reported [58, 59, 68] significantly higher prevalence of anxiety and hostility in female methadone maintenance treatment patients compared to males. In terms of drug abuse duration, a fairly large proportion of participants in our study reported having a history of addiction since before the age of 15 , necessitating the implementation of prevention strategies among young people [70, 71]. However, in agreement with other authors $[63,68]$ drug abuse duration does not have significant influence on psychopathology scales, as if a kind of adaptability develops.

Coexisting psychopathology substantially affects quality of life $[72,73]$ and authors recommend $[29,74]$ that selfreported psychopathology should be routinely evaluated in order to improve health-related quality of life in comprehensive treatment programs for heroin abusers.

The relationship between addictive disorders and other forms of psychopathology has long been debated since it may involve such a close interaction at neurobiological levels between predisposing factors, addictive processes, and addictive consequences that the attempt to clinically distinguish between addictive-related and independent psychopathological symptoms may turn out to be little more than an inconclusive theoretical exercise. This is the reason that the application of the classic model of psychiatric comorbidity in the field of addiction has been the target of criticism owing to the difficulty of disentangling supposedly independent psychiatric symptoms and syndromes from the core psychopathology of addiction [75-77].

Another important issue is the prevalence of alcohol abuse and dependence which is increasingly acknowledged $[12,78-82]$ in methadone maintenance treatment settings, adversely affecting their program compliance and physical and mental health. Among the variables associated with alcohol use by methadone patients is psychiatric symptomatology. Alcoholics scored higher [78] than nonalcoholics on six subscales of the Brief Symptom Inventory (BSI): somatization, obsessions-compulsions behavior, depression, anxiety, phobic anxiety, and psychotic symptoms, but authors comment that because the findings are correlational, reported psychopathology might be an alcohol-induced artifact that is secondary to dependence.

In the predictive model of our study, $9 \%$ of the variance of scores on AUDIT was attributed to somatization subscale from SCL-90R and years on methadone treatment explained an additional $4 \%$ of the variance. Somatization in drug addicts is distinguished by a number of somatic and anxious elements, which are usually a feature of opiate withdrawal. In the late $90 \mathrm{~s}$ it was proposed that alcohol abuse during methadone maintenance treatment might result from inadequate methadone dose [11] or that chronic alcohol use increases CYP450 3A4 metabolism of methadone resulting in the need for increasing dose being required to sustain effective methadone serum levels. Alcohol abuse was alleged to occur when dosage is likely sufficient to control most withdrawal symptoms and block opioid-related euphoria, due to cross tolerance, but is not sufficient to control drug craving. Witkiewitz [83] stated that proximal risk factors, such as craving, mood, and stress, are associated with distal risk factors, such as psychological distress, possibly leading to continued substance and alcohol use. The theory was that patients initiate or increase their use of alcohol in order to achieve a change in their moods or function that was no longer accessible to them through opioid abuse, providing an alternative rewarding effect. Also since daily urinalyses informed about their actual heroin use status in order to remain on methadone maintenance, a condition is brought about in which abuse of alcohol becomes more rewarding than opioid abuse.

Results from other studies $[16,84,85]$ indicate that drinking problems among patients undergoing methadone maintenance treatment are associated with an increased risk of relapse into illicit drug use and with discharge from treatment. Authors suggest that concurrent treatment of alcohol-related problems including systematic monitoring of alcohol use should be recommended [86-88] to reduce the risk for relapse into illicit drug use and improve overall treatment outcome in methadone maintenance treatment settings, especially among patients with personality disorders [89-91].

In sum, our study indicates the presence of high rates of psychopathological symptoms along with problematic alcohol use among drug addicts that hinders the positive outcome of therapeutic efforts in substitution programs. This should be taken into account during the therapeutic treatment process, so as to implement the most effective and most intensive interventions [92-94].

\section{Limitations}

The limited number of participants compared with the total number of drug addicts treated in all Substitution Units of our country may compromise the generalizability of our findings and additional extended surveys are required to conclude more accurately.

It is also important to emphasize that the results of the present study evidence psychiatric symptomatology and not psychiatric diagnosis among drug addicts on methadone maintenance treatment owing to lack of necessary diagnostic tools but beyond this owing primarily to lack of information about concurrent substance abuse among participants leading them to experience relevant intoxication or withdrawal symptoms which might have affected their answers in applied questionnaires.

\section{Conclusions}

High levels of psychological distress along with high prevalence of alcohol-related problems are evidenced among drug addicts on Methadone Substitution Treatment Programs, in Greece. Moreover the fact that our research was conducted in a time of economic crisis, with limited work opportunities, provides a further explanation for the high unemployment rates in our sample. Targeting ancillary psychosocial services 
[95-97] which focus on legal, educational, vocational, recreational, financial, and family issues, as well as interpersonal difficulties, would be beneficial for this population. These factors should all be addressed in order to provide a more flexible approach and improved delivery of these needed, lifesaving services.

\section{Conflict of Interests}

The authors declare that they have no competing interests.

\section{References}

[1] European Monitoring Center for Drugs and Addiction (EMCDDA), Annual Report 2012: The State of the Drugs and Alcohol Problem in Greece, 2013.

[2] European Monitoring Center for Drugs and Addiction (EMCDDA), Annual Report 2011: The State of the Drugs and Alcohol Problem in Greece, 2011.

[3] University Mental Health Research Institute, European School Survey Project on Alcohol and other Drugs (ESPAD) 2011, UMHRI, Athens, Greece, 2012.

[4] University Mental Health Research Institute (UMHRI), 2011 National Report (2010 Data) to the EMCDDA by the Reitox National Focal Point, New Development, Trends and InDepth Information on Selected Issues, University Mental Health Research Institute, Athens, Greece, 2011.

[5] University Mental Health Research Institute (UMHRI), Annual Report 2013: The State of the Drugs and Alcohol Problem in Greece, Athens, University Mental Health Research Institute (UMHRI), 2014.

[6] Organization against drugs, Report on the 2010-2012 activities.

[7] D. A. Regier, M. E. Farmer, D. S. Rae et al., "Comorbidity of mental disorders with alcohol and other drug abuse. Results from the epidemiologic catchment area (ECA) Study," The Journal of the American Medical Association, vol. 264, no. 19, pp. 2511-2518, 1990.

[8] B. J. Rounsaville, H. R. Kranzler, S. Ball, H. Tennen, J. Poling, and E. Triffleman, "Personality disorders in substance abusers: relation to substance use," Journal of Nervous and Mental Disease, vol. 186, no. 2, pp. 87-95, 1998.

[9] B. F. Grant, F. S. Stinson, D. A. Dawson et al., "Prevalence and co-occurrence of substance use disorders and independent mood and anxiety disorders: results from the National Epidemiologic Survey on Alcohol and Related Conditions," Archives of General Psychiatry, vol. 61, no. 8, pp. 807-816, 2004.

[10] R. K. Brooner, V. L. King, M. Kidorf, C. W. Schmidt, and G. E. Bigelow, "Psychiatric and substance use comorbidity among treatment-seeking opioid abusers," Archives of General Psychiatry, vol. 54, no. 1, pp. 71-80, 1997.

[11] I. Maremmani, P. P. Pani, A. Mellini et al., "Alcohol and cocaine use and abuse among opioid addicts engaged in a Methadone Maintenance Treatment Program," Journal of Addictive Diseases, vol. 26, no. 1, pp. 61-70, 2007.

[12] H. G. Fulton, S. P. Barrett, C. MacIsaac, and S. H. Stewart, "The relationship between self-reported substance use and psychiatric symptoms in low-threshold methadone maintenance treatment clients," Harm Reduction Journal, vol. 8, article 18, 2011.
[13] A. Kokkevi and C. Stefanis, "Drug abuse and psychiatric comorbidity," Comprehensive Psychiatry, vol. 36, no. 5, pp. 329-337, 1995.

[14] J. Ross, M. Teesson, S. Darke et al., "The characteristics of heroin users entering treatment: Findings from the Australian treatment outcome study (ATOS)," Drug and Alcohol Review, vol. 24, no. 5, pp. 411-418, 2005.

[15] A. Hassel, T. Nordfærn, and R. Hagen, "Psychological and interpersonal distress among patients with substance use disorders: are these factors associated with continued drug use and do they change during treatment?" Journal of Substance Use, vol. 18, no. 5, pp. 363-376, 2013.

[16] D. K. Roszell, D. A. Calsyn, and E. F. Chaney, "Alcohol use and psychopathology in opioid addicts on methadone maintenance," The American Journal of Drug and Alcohol Abuse, vol. 12, no. 3, pp. 269-278, 1986.

[17] A. Bleich, M. Gelkopf, V. Schmidt, R. Hayward, G. Bodner, and M. Adelson, "Correlates of benzodiazepine abuse in methadone maintenance treatment. A 1 year prospective study in an Israeli clinic," Addiction, vol. 94, no. 10, pp. 1533-1540, 1999.

[18] A. Dobler-Mikola, J. Hättenschwiler, D. Meili, T. Beck, E. Böni, and J. Modestin, "Patterns of heroin, cocaine, and alcohol abuse during long-term methadone maintenance treatment," Journal of Substance Abuse Treatment, vol. 29, no. 4, pp. 259-265, 2005.

[19] B. Brands, J. Blake, B. Sproule, D. Gourlay, and U. Busto, "Prescription opioid abuse in patients presenting for methadone maintenance treatment," Drug and Alcohol Dependence, vol. 73, no. 2, pp. 199-207, 2004.

[20] X. Laqueille, C. Launay, A. Dervaux, and M. Kanit, "Abuse of alcohol and benzodiazepine during substitution therapy in heroin addicts: a review of the literature," Encephale, vol. 35, no. 3, pp. 220-225, 2009.

[21] B. J. Mason, J. H. Kocsis, D. Melia et al., "Psychiatric comorbidity in methadone maintained patients," Journal of Addictive Diseases, vol. 17, no. 3, pp. 75-89, 1998.

[22] I. Maremmani, O. Zolesi, M. Aglietti, G. Marini, A. Tagliamonte, and S. Maxwell, "Methadone dose and retention during treatment of heroin addicts with Axis I psychiatric comorbidity," Journal of Addictive Diseases, vol. 19, no. 2, pp. 29-41, 2000.

[23] E. C. Strain, G. E. Bigelow, I. A. Liebson, and M. L. Stitzer, "Moderate- vs high-dose methadone in the treatment of opioid dependence: a randomized trial," The Journal of the American Medical Association, vol. 281, no. 11, pp. 1000-1005, 1999.

[24] N. Parvaresh, A. Masoudi, S. Majidi-Tabrizi, and S. Mazhari, "The correlation between methadone dosage and comorbid psychiatric disorders in patients on methadone maintenance treatment," Addiction \& Health, vol. 4, no. 1-2, pp. 1-8, 2012.

[25] M. Gelkopf, T. Weizman, Y. Melamed, M. Adelson, and A. Bleich, "Does psychiatric comorbidity affect drug abuse treatment outcome? A prospective assessment of drug abuse, treatment tenure and infectious diseases in an Israeli methadone maintenance clinic," Israel Journal of Psychiatry and Related Sciences, vol. 43, no. 2, pp. 126-136, 2006.

[26] P. J. Carpentier, P. F. M. Krabbe, M. T. van Gogh, L. J. M. Knapen, J. K. Buitelaar, and C. A. J. de Jong, "Psychiatric comorbidity reduces quality of life in chronic methadone maintained patients," American Journal on Addictions, vol. 18, no. 6, pp. 470480, 2009.

[27] M. Astals, A. Domingo-Salvany, C. C. Buenaventura et al., "Impact of substance dependence and dual diagnosis on the quality of life of heroin users seeking treatment," Substance Use and Misuse, vol. 43, no. 5, pp. 612-632, 2008. 
[28] Y.-Z. Chen, W.-L. Huang, J.-C. Shan, Y.-H. Lin, H.-C. W. Chang, and L.-R. Chang, "Self-reported psychopathology and healthrelated quality of life in heroin users treated with methadone," Neuropsychiatric Disease and Treatment, vol. 9, no. 1, pp. 41-48, 2013.

[29] A. Karow, U. Verthein, R. Pukrop et al., "Quality of life profiles and changes in the course of maintenance treatment among 1,015 patients with severe opioid dependence," Substance Use and Misuse, vol. 46, no. 6, pp. 705-715, 2011.

[30] J. P. Feelemyer, D. C. D. Jarlais, K. Arasteh, B. W. Phillips, and H. Hagan, "Changes in quality of life (WHOQOL-BREF) and addiction severity index (ASI) among participants in opioid substitution treatment (OST) in low and middle income countries: an international systematic review," Drug and Alcohol Dependence, vol. 134, no. 1, pp. 251-258, 2014.

[31] A. T. McLellan, L. Luborsky, G. E. Woody, C. P. O’Brien, and K. A. Druley, "Predicting response to alcohol and drug abuse treatments. Role of psychiatric severity," Archives of General Psychiatry, vol. 40, no. 6, pp. 620-625, 1983.

[32] S. Darke, "The effectiveness of methadone maintenance treatment 3: moderators of treatment outcome," in Methadone Maintenance Treatment and Other Opioid Replacement Therapies, J. Ward, R. P. Mattick, and W. Hall, Eds., pp. 75-89, Harwood Academic Publishers, Amsterdam, The Netherlands, 1998.

[33] A. T. McLellan, A. R. Childress, J. Griffith, and G. E. Woody, "The psychiatrically severe drug abuse patient: methadone maintenance or therapeutic community?" The American Journal of Drug and Alcohol Abuse, vol. 10, no. 1, pp. 77-95, 1984.

[34] B. J. Rounsaville, T. R. Kosten, M. M. Weissman, and H. D. Kleber, "Prognostic significance of psychopathology in treated opiate addicts. A 2.5-year follow-up study," Archives of General Psychiatry, vol. 43, no. 8, pp. 739-745, 1986.

[35] J. S. Cacciola, A. I. Alterman, M. J. Rutherford, J. R. McKay, and F. D. Mulvaney, "The relationship of psychiatric comorbidity to treatment outcomes in methadone maintained patients," Drug and Alcohol Dependence, vol. 61, no. 3, pp. 271-280, 2001.

[36] G. E. Woody, A. T. McLellan, L. Luborsky et al., "Severity of psychiatric symptoms as a predictor of benefits from psychotherapy: the Veterans Administration-Penn study," American Journal of Psychiatry, vol. 141, no. 10, pp. 1172-1177, 1984.

[37] U. Verthein, P. Degkwitz, C. Haasen, and M. Krausz, "Significance of comorbidity for the long-term course of opiate dependence," European Addiction Research, vol. 11, no. 1, pp. 1521, 2005.

[38] P. P. Pani, E. Trogu, P. Contu, A. Agus, and G. L. Gessa, "Psychiatric severity and treatment response in a comprehensive methadone maintenance treatment program," Drug and Alcohol Dependence, vol. 48, no. 2, pp. 119-126, 1997.

[39] P. P. Pani, I. Maremmani, M. Pacini, F. Lamanna, A. G. I. Maremmani, and L. Dell'Osso, "Effect of psychiatric severity on the outcome of methadone maintenance treatment," European Addiction Research, vol. 17, no. 2, pp. 80-89, 2011.

[40] M. Astals, L. Díaz, A. Domingo-Salvany, R. Martín-Santos, A. Bulbena, and M. Torrens, "Impact of co-occurring psychiatric disorders on retention in a methadone maintenance program: an 18-month follow-up study," International Journal of Environmental Research and Public Health, vol. 6, no. 11, pp. 2822-2832, 2009.

[41] I. Schäfer, M. Fischer, J. Reimer, A. Karow, and C. Haasen, "Significance of psychiatric comorbidity for the outcome of maintenance treatment-a review of the literature," Mental Health and Substance Use, vol. 4, no. 1, pp. 62-71, 2011.
[42] H.-Y. Lee, J.-H. Li, Y.-L. Sheu et al., "Moving toward personalized medicine in the methadone maintenance treatment program: a pilot study on the evaluation of treatment responses in Taiwan," BioMed Research International, vol. 2013, Article ID 741403, 11 pages, 2013.

[43] G. C. Urbaniak and S. Plous, Research Randomizer (Version 4.0), Computer software, 2013, http://www.randomizer.org/.

[44] L. R. Derogatis, R. S. Lipman, and L. Covi, "SCL-90: an outpatient psychiatric rating scale-preliminary report," Psychopharmacology Bulletin, vol. 9, no. 1, pp. 13-28, 1973.

[45] L. R. Derogatis, Symptom Checklist-90-R Administration, Scoring and Procedures Manual II, Clinical Psychometric Research, Towson, Md, USA, 1983.

[46] L. R. Derogatis, Handbook of Psychiatric Measures, American Psychiatric Association, Arlington, Va, USA, 2000.

[47] G. Vitoratou, Standardization and analysis of psychometric characteristics of recruit reserve officers [M.S. thesis], Department of Mathematics, University of Athens Medical School, Athens, Greece, 2004, (Greek).

[48] K. Giotakis, A. Douzenis, A. Tselebis et al., "Psychological parameters and habitual smoking among health professionals," Encephalos, vol. 50, no. 3, pp. 82-88, 2013.

[49] A. Tselebis, D. Bratis, E. Kosmas et al., "Psychological symptom patterns and vital exhaustion in outpatients with chronic obstructive pulmonary disease," Annals of General Psychiatry, vol. 10, article 32, 2011.

[50] A. Tselebis, E. Kosmas, D. Bratis et al., "Contribution of psychological factors in dropping out from chronic obstructive pulmonary disease rehabilitation programs," BioMed Research International, vol. 2014, Article ID 401326, 6 pages, 2014.

[51] S. Donias, A. Karastergiou, and N. Manos, "Standardization of the symptom checklist-90-R rating scale in a Greek population," Psychiatriki, vol. 2, no. 1, pp. 42-48, 1991 (Greek).

[52] H. E. Klugh, "Normalized T scores," in Encyclopedia of Statistical Sciences, S. Kotz, C. B. Read, N. Balakrishnan, and B. Vidakovic, Eds., John Wiley \& Sons, New York, NY, USA, 2nd edition, 2006.

[53] W. A. McCall, How to Measure in Education, Macmillan, New York, NY, USA, 1922.

[54] J. B. Saunders, O. G. Aasland, T. F. Babor, J. R. de la Fuente, and M. Grant, "Development of the alcohol use disorders identification test (AUDIT): WHO collaborative project on early detection of persons with harmful alcohol consumption II," Addiction, vol. 88, no. 6, pp. 791-804, 1993.

[55] T. F. Babor, J. C. Higgins-Biddle, J. B. Saunders et al., AUDITThe Alcohol Use Disorder Identification Test: Guidelines for Use in Primary Health Care, Department of Mental Health and Substance Abuse, World Health Organization, Geneva, Switzerland, 2nd edition, 2001.

[56] G. Moussas, G. Dadouti, A. Douzenis et al., "Reliability and validity of the Greek version of the alcohol use disorders identification test (AUDIT)," Psychiatriki, vol. 21, no. 1, pp. 54$59,2010$.

[57] G. Moussas, G. Dadouti, A. Douzenis et al., "The Alcohol Use Disorders Identification Test (AUDIT): reliability and validity of the Greek version," Annals of General Psychiatry, vol. 8, article 11, 2009.

[58] P. E. Jacobs, E. B. Doft, and J. Koger, "A study of SCL-90 scores of 264 methadone patients in treatment," International Journal of the Addictions, vol. 16, no. 3, pp. 541-548, 1981. 
[59] P. P. Pani, E. Trogu, F. Vigna-Taglianti et al., "Psychopathological symptoms of patients with heroin addiction entering opioid agonist or therapeutic community treatment," Annals of General Psychiatry, vol. 13, article 35, 2014.

[60] L. R. Chatham, M. L. Hiller, G. A. Rowan-Szal, G. W. Joe, and D. D. Simpson, "Gender differences at admission and follow-up in a sample of methadone maintenance clients," Substance Use and Misuse, vol. 34, no. 8, pp. 1137-1165, 1999.

[61] F. J. Eiroá-Orosa, U. Verthein, S. Kuhn et al., "Implication of gender differences in heroin-assisted treatment: results from the German randomized controlled trial," The American Journal on Addictions, vol. 19, no. 4, pp. 312-318, 2010.

[62] M. Bawor, B. B. Dennis, R. Anglin, M. Steiner, L. Thabane, and Z. Samaan, "Sex differences in outcomes of methadone maintenance treatment for opioid addiction: a systematic review protocol," Systematic Reviews, vol. 3, article 45, 2014.

[63] I. Maremmani, P. P. Pani, M. Pacini et al., "Subtyping patients with heroin addiction at treatment entry: factor derived from the Self-Report Symptom Inventory (SCL-90)," Annals of General Psychiatry, vol. 9, article 15, 2010.

[64] H. Joseph, S. Stancliff, and J. Langrod, "Methadone maintenance treatment (MMT): A review of historical and clinical issues," The Mount Sinai Journal of Medicine, vol. 67, no. 5-6, pp. 347364, 2000.

[65] G. T. Ray, J. R. Mertens, and C. Weisner, "Family members of people with alcohol or drug dependence: health problems and medical cost compared to family members of people with diabetes and asthma," Addiction, vol. 104, no. 2, pp. 203-214, 2009.

[66] D. Simpson, "National treatment system evaluation based on the drug abuse reporting program (DARP) follow-up research," in Drug Abuse Treatment Evaluation: Strategies, Progress and Prospects, F. M. Tims and J. P. Ludford, Eds., vol. 51, pp. 6679, National lnstitute on Drug Abuse Research Monograph, Rockville, Md, USA, 1984.

[67] A. Paraherakis, Substance-related disorders and associated psychopathology: predicting addictions treatment outcome [M.S. thesis], Faculty of Graduate Studies and Research, McGill University, Montréal, Canada, 1997.

[68] S. M. Y. Ardakani, S. Banaei-Boroujeni, and G. Dastjerdi, "Psychiatric disorders prevalence comparison in opiate-dependent and non-opiate dependent individuals," Journal of Addiction Research \& Therapy, no. S8, article 5, 2013.

[69] B. S. McCrady, "To have but one true friend: Implications for practice of research on alcohol use disorders and social networks," Psychology of Addictive Behaviors, vol. 18, no. 2, pp. 113-121, 2004.

[70] J. M. O’neill, J. K. Clark, and J. A. Jones, "Promoting mental health and preventing substance abuse and violence in elementary students: a randomized control study of the michigan model for health," Journal of School Health, vol. 81, no. 6, pp. 320-330, 2011.

[71] E. Kiss, B. Pikó, and A. Vetró, "Frequency of smoking, drinking, and substance use and their relationship to psychiatric comorbidity in depressed child and adolescent population," Psychiatria Hungarica, vol. 21, no. 5, pp. 371-378, 2006.

[72] U. Frischknecht, B. Beckmann, M. Heinrich et al., "The vicious circle of perceived stigmatization, depressiveness, anxiety, and low quality of life in substituted heroin addicts," European Addiction Research, vol. 17, no. 5, pp. 241-249, 2011.

[73] C.-N. Yen, C. S.-M. Wang, T.-Y. Wang, H.-F. Chen, and H.-C. Chang, "Quality of life and its correlates among heroin users in
Taiwan," Kaohsiung Journal of Medical Sciences, vol. 27, no. 5, pp. 177-183, 2011.

[74] H. S. Esfandabada, S. Nejadnaderi, and S. Emamipour, "Assessment of quality of life and psychological disorder symptoms among opium-dependent men on buprenorphine detoxification," Procedia-Social and Behavioral Sciences, vol. 5, pp. 13961399, 2010.

[75] I. Maremmani, P. P. Pani, A. G. I. Maremmani et al., "Psychopathological symptoms of heroin addicts at treatment entry," Heroin Addiction and Related Clinical Problems, vol. 15, no. 2, pp. 37-46, 2013.

[76] P. P. Pani, "Addiction: challenging the dual diagnosis construct," Heroin Addiction and Related Clinical Problems, vol. 12, no. 2, pp. 5-8, 2010.

[77] P. P. Pani, I. Maremmani, E. Trogu, G. L. Gessa, P. Ruiz, and H. S. Akiskal, "Delineating the psychic structure of substance abuse and addictions: should anxiety, mood and impulse-control dysregulation be included?" Journal of Affective Disorders, vol. 122, no. 3, pp. 185-197, 2010.

[78] N. El-Bassel, R. F. Schilling, J. E. Turnbull, and K.-H. Su, "Correlates of alcohol use among methadone patients," Alcoholism: Clinical and Experimental Research, vol. 17, no. 3, pp. 681-686, 1993.

[79] S. G. Craddock, J. L. Rounds-Bryant, P. M. Flynn, and R. L. Hubbard, "Characteristics and pre-treatment behaviors of clients entering drug abuse treatment: 1969 to 1993," The American Journal of Drug and Alcohol Abuse, vol. 23, no. 1, pp. 43-59, 1997.

[80] H. Rittmannsberger, C. Silberbauer, R. Lehner, and M. Ruschak, "Alcohol consumption during methadone maintenance treatment," European Addiction Research, vol. 6, no. 1, pp. 2-7, 2000.

[81] H. Joseph and P. Appel, "Alcoholism and methadone treatment: consequences for the patient and program," The American Journal of Drug and Alcohol Abuse, vol. 11, no. 1-2, pp. 37-53, 1985.

[82] I.-C. Chen, W.-C. Chie, H.-G. Hwu et al., "Alcohol use problem among patients in methadone maintenance treatment in Taiwan," Journal of Substance Abuse Treatment, vol. 40, no. 2, pp. 142-149, 2011.

[83] K. Witkiewitz, "Predictors of heavy drinking during and following treatment," Psychology of Addictive Behaviors, vol. 25, no. 3, pp. 426-438, 2011.

[84] D. D. Brewer, R. F. Catalano, K. Haggerty, R. R. Gainey, and C. B. Fleming, "A meta-analysis of predictors of continued drug use during and after treatment for opiate addiction," Addiction, vol. 93, no. 1, pp. 73-92, 1998.

[85] M. Stenbacka, O. Beck, A. Leifman, A. Romelsjö, and A. Helander, "Problem drinking in relation to treatment outcome among opiate addicts in methadone maintenance treatment," Drug and Alcohol Review, vol. 26, no. 1, pp. 55-63, 2007.

[86] I. Siassi and D. C. Alston, "Methadone maintenance and the problem with alcohol," The American Journal of Drug and Alcohol Abuse, vol. 3, no. 2, pp. 267-277, 1976.

[87] D. Teplin, B. Raz, J. Daiter, M. Varenbut, and C. PlaterZyberk, "Screening for alcohol use patterns among methadone maintenance patients," American Journal of Drug and Alcohol Abuse, vol. 33, no. 1, pp. 179-183, 2007.

[88] J. Hillebrand, J. Marsden, E. Finch, and J. Strang, "Excessive alcohol consumption and drinking expectations among clients in methadone maintenance," Journal of Substance Abuse Treatment, vol. 21, no. 3, pp. 155-160, 2001. 
[89] L. Öhlin, M. Hesse, M. Fridell, and P. Tätting, "Poly-substance use and antisocial personality traits at admission predict cumulative retention in a buprenorphine programme with mandatory work and high compliance profile," BMC Psychiatry, vol. 11, article 81, 2011.

[90] M. J. Rutherford, J. S. Cacciola, and A. I. Alterman, "Relationships of personality disorders with problem severity in methadone patients," Drug and Alcohol Dependence, vol. 35, no. 1, pp. 69-76, 1994.

[91] S. A. Ball, "Comparing individual therapies for personality disordered opioid dependent patients," Journal of Personality Disorders, vol. 21, no. 3, pp. 305-321, 2007.

[92] L. E. Wüsthoff, H. Waal, and R. W. Gråwe, "The effectiveness of integrated treatment in patients with substance use disorders co-occurring with anxiety and/or depression-a group randomized trial," BMC Psychiatry, vol. 14, no. 1, article 67, 2014.

[93] M. Nalaskowska and L. Cierpiałkowska, "Social and psychological functioning of opiate dependent patients in methadone maintenance treatment-longitudinal research report," Alcoholism and Drug Addiction, vol. 27, no. 3, pp. 237-254, 2014.

[94] E. Wu, N. El-Bassel, L. Gilbert, M. Chang, and G. Sanders, "Effects of receiving additional off-site services on abstinence from illicit drug use among men on methadone: a longitudinal study," Evaluation and Program Planning, vol. 33, no. 4, pp. 403409, 2010.

[95] A. T. McLellan, I. O. Arndt, D. S. Metzger, G. E. Woody, and C. P. O'Brien, "The effects of psychosocial services in substance abuse treatment," Journal of the American Medical Association, vol. 269, no. 15, pp. 1953-1959, 1993.

[96] L. Goehl, E. Nunes, F. Quitkin, and I. Hilton, "Social networks and methadone treatment outcome: the costs and benefits of social ties," The American Journal of Drug and Alcohol Abuse, vol. 19, no. 3, pp. 251-262, 1993.

[97] T. Nordfiærn, R. Hole, and T. Rundmo, "Interrelations between patients' personal life events, psychosocial distress, and substance use," Substance Use \& Misuse, vol. 45, no. 7-8, pp. 1161$1179,2010$. 


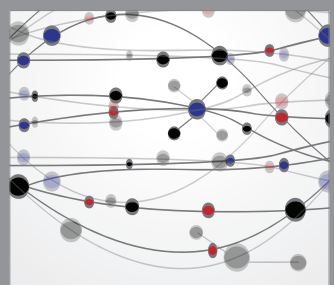

The Scientific World Journal
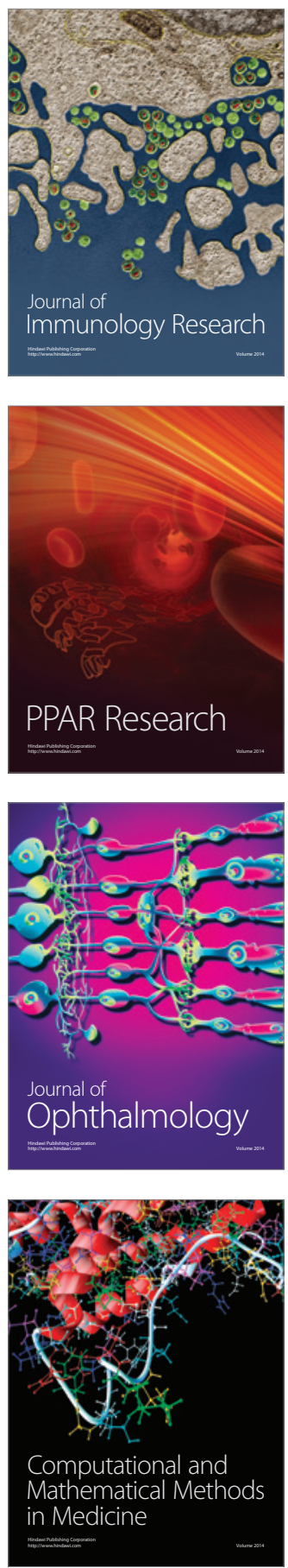

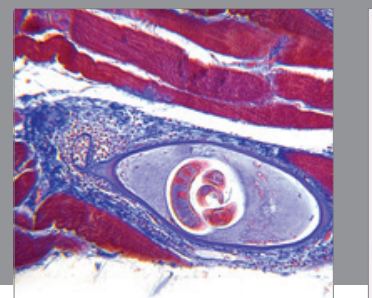

Gastroenterology

Research and Practice
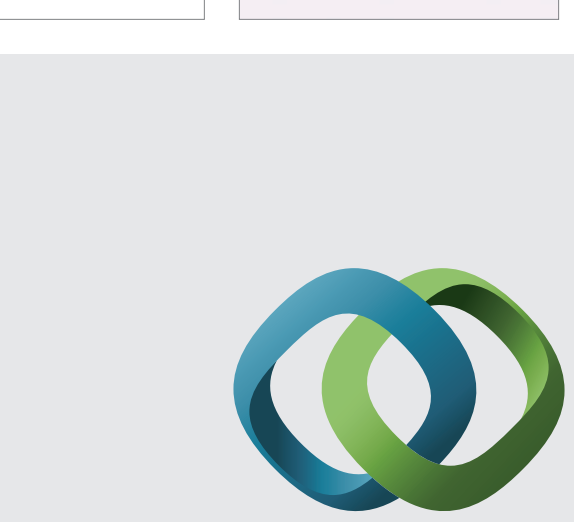

\section{Hindawi}

Submit your manuscripts at

http://www.hindawi.com
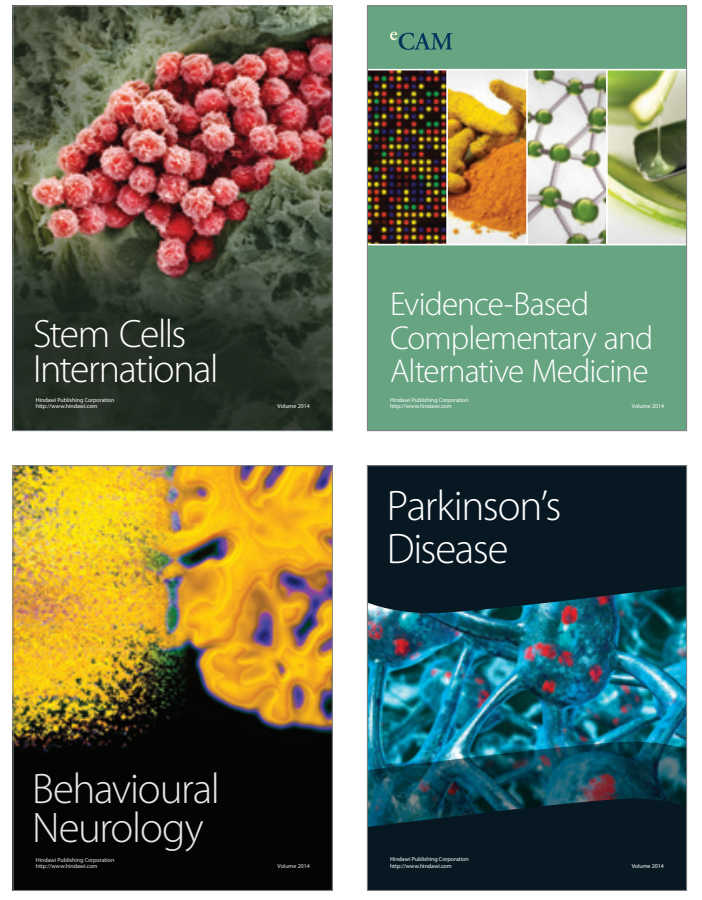
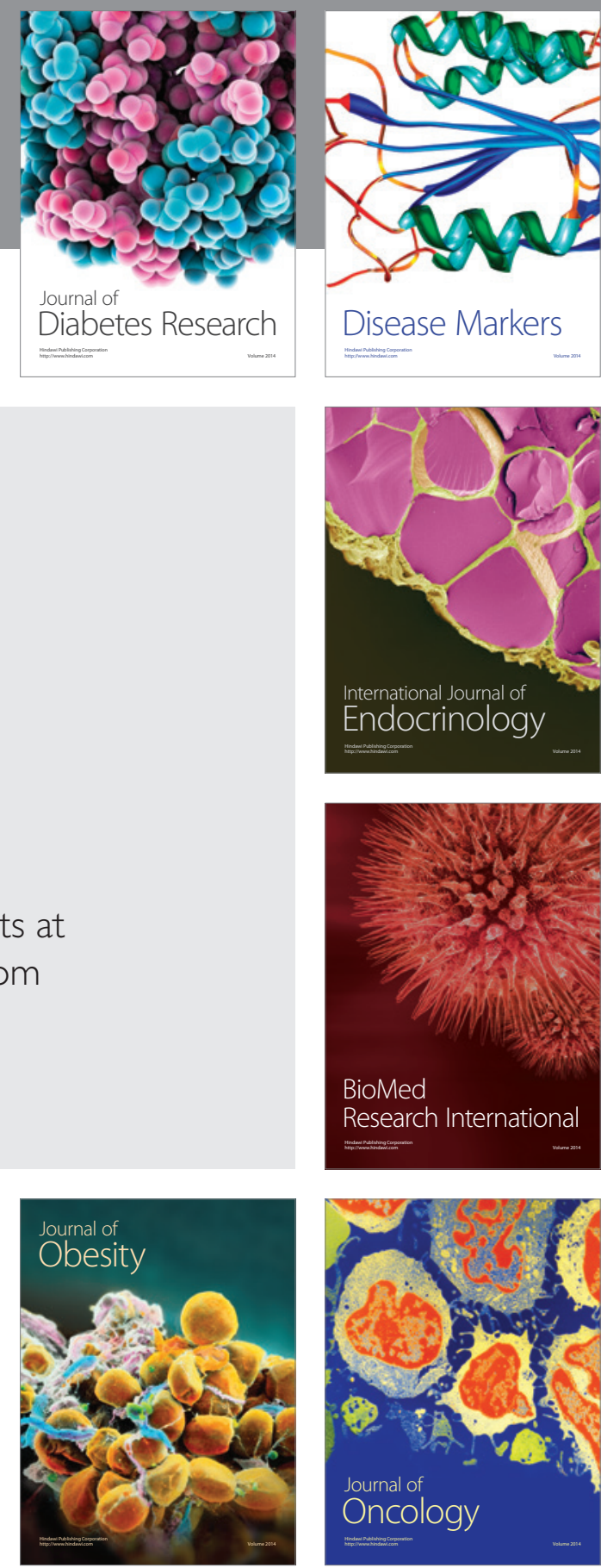

Disease Markers
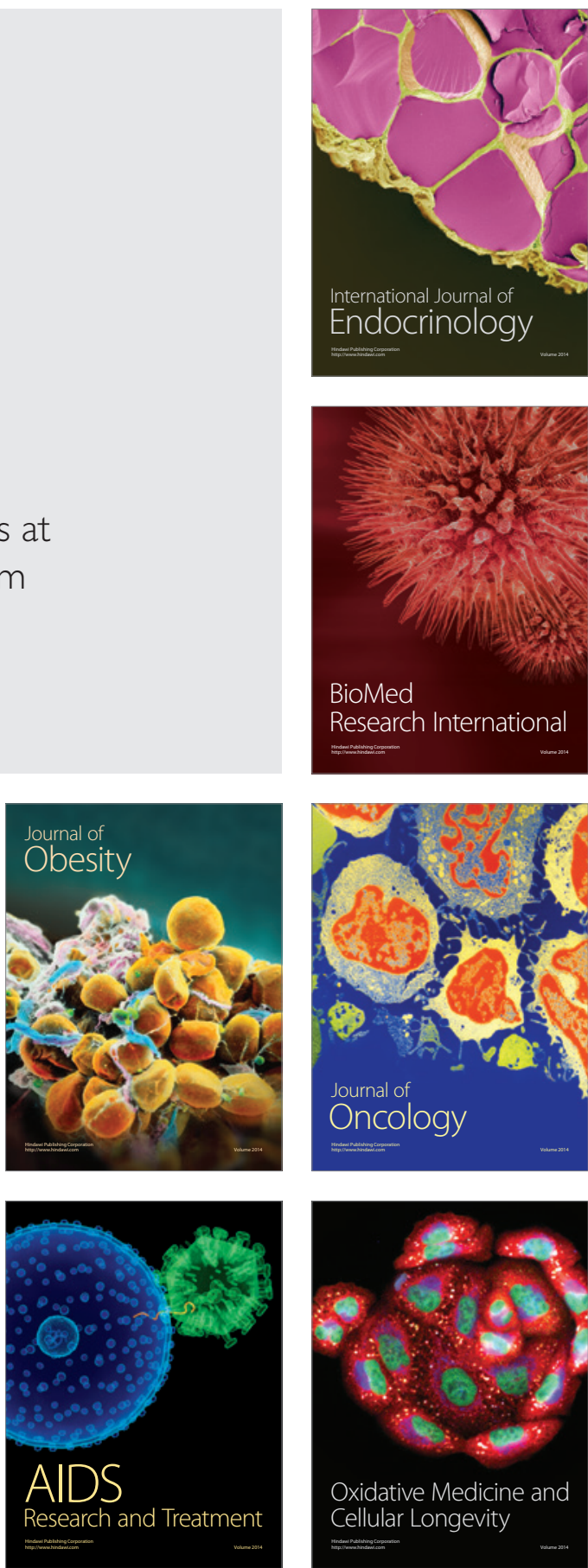